Research Article

\title{
Research on Mechanical, Physicochemical and Electrical Properties of XLPE-Insulated Cables under Electrical- Thermal Aging
}

\author{
Dongxin He $\mathbb{D}^{1},{ }^{1}$ Tao Zhang, ${ }^{1}$ Meng Ma, ${ }^{1}$ Wenjie Gong, ${ }^{1}$ Wei Wang, ${ }^{2}$ and Qingquan Li ${ }^{1}$ \\ ${ }^{1}$ Shandong Provincial Key Laboratory of UHV Transmission Technology and Equipment, School of Electrical Engineering, \\ Shandong University, Jinan 250061, China \\ ${ }^{2}$ Beijing Key Laboratory of High Voltage \& Electromagnetic Compatibility, State Key Laboratory of Alternate Electrical Power System \\ with Renewable Energy Sources, North China Electric Power University, Beijing 102206, China
}

Correspondence should be addressed to Dongxin He; hedongxin@yeah.net

Received 16 May 2019; Revised 7 December 2019; Accepted 11 January 2020; Published 3 February 2020

Academic Editor: Zehra Durmus

Copyright (C) 2020 Dongxin He et al. This is an open access article distributed under the Creative Commons Attribution License, which permits unrestricted use, distribution, and reproduction in any medium, provided the original work is properly cited.

\begin{abstract}
The stabilization of cross-linked polyethylene (XLPE) cables is crucial to the safe working of power systems. In order to investigate the aging characteristics of cable insulation in the process of operation, $10 \mathrm{kV}$ XLPE cables were electrically-thermally aged at an AC voltage of $26.1 \mathrm{kV}$ and three temperatures: $103^{\circ} \mathrm{C}, 114^{\circ} \mathrm{C}$, and $135^{\circ} \mathrm{C}$. Cable samples at five aging stages were cut into slices and tested to determine their mechanical, physicochemical properties and dielectric strength. The changes in these properties were analyzed in terms of aging time. The mechanical strength and oxidation induction time have the same changing trend of decrease, because the chemical bonds of the cable insulation material are fractured when the XLPE cable is aged. The AC space charge presented a trend of gradual accumulation with aging time. The breakdown field strength after AC voltage application decreases monotonically with aging time, which could be a characteristic index to evaluate the degradation degree of the cable insulation. This research contributes to the comprehension of degradation mechanism and discovery of aging assessment criteria, which is of great significance in assessments of insulation properties and fault detection on power cables.
\end{abstract}

\section{Introduction}

Commonly used power cables can be divided by their type of insulation into the categories of oil-paper insulated cables, rubber insulated cables, and plastic insulated cables. Plastic insulated cables can be further divided into polyvinyl chloride (PVC) insulated cables, polyethylene (PE) insulated cables, and cross-linked polyethylene (XLPE) insulated cables. Of these, XLPE-insulated cables have become the dominant power cable variety. In recent years, they have been widely used in power transmission and distribution grid systems, because of the relatively simple manufacturing process and their excellent mechanical, electrical, and thermal performance $[1,2]$. During use, cables are affected by electricity, heat, moisture, and other factors that result from aging and electrical performance degradation. This eventually leads to cable breakdowns and can seriously be harmful to the safe and stable operation of the power grid [3]. Therefore, the degradation mechanism of cable insulation under electrical and thermal effects is important when evaluating the degree of degradation and fault detection in a cable.

In laboratory conditions, the accelerated electricalthermal aging method is typically used for research into the aging characteristics of insulation materials [4]. There have been a number of studies of the effects of accelerated thermal or electrical aging on low-density PE or XLPE film material. It has been found that part of the film specimens for aging is from low-density polyethylene powder hot pressing [5] and that part of the film specimens is cut off from the actual cable insulation [6]. The aging process for cable insulation can, to some extent, be simulated through aging tests in PE film material. There are some experimental results about thermal aging and electrical aging. Shwehdi et al. studied thermal aging of PVC and XLPE samples [7]. Bessissa et al. 
proposed a fuzzy logic method for predicting cable life under thermal aging [8]. Zhan et al. studied the relationship between structural changes and dielectric strength of cable insulation under thermal oxidative aging [9]. Wang et al. and others studied the space charge characteristics of XPLE films under long-term DC voltage and high temperature [10].

There are some differences in the aging environments of PE film materials and XLPE cable coaxial insulation [11]. Specifically, the surface of the film material under aging is in direct contact with either air or insulating oil, while the cable insulation is isolated from the air by the outer shielding layer. This can lead to changes in the aging mechanism. It is difficult to reflect the aging mechanisms of cable insulation by only testing the PE film material. Therefore, it is significant to study the aging characteristics on real cable coaxial insulation. Montanari et al. at the University of Bologna looked at $1.5 \mathrm{~mm}$ thick XLPEinsulation cables and researched the long-term behavior of the cable under electrical-thermal aging. The experiment examined the method of density, melting enthalpy, electric strength, and SEM (scanning electron microscope) $[12,13]$. However, a $1.5 \mathrm{~mm}$ thick XLPE-insulation cable is very thinly insulated and is not suitable in power distribution network systems ( $\geq 6 \mathrm{kV}$ and $2.5 \mathrm{~mm}$ thick XLPE insulation).

At present, the research of cable insulation aging is limited to a single aging method such as electrical aging or thermal aging $[14,15]$. There is little research conducted on aging of cable insulation under combined electrical-thermal stress. In addition, the research object of insulation material aging is mostly sliced material rather than cable $[16,17]$, which may result in deviation from the result of field operation. Right now, research on electrical-thermal aging of power transmission cables is still blank. Thus, the electrical-thermal aging mechanism of the whole cable is not clear so far. Therefore, further study is necessary to explore the aging mechanism of cable insulation and propose an early warning scheme for cable insulation deterioration.

In order to study the degradation mechanism of power cables under the combined effects of heat and electricity, we carried out an electrical-thermal aging test on a $10 \mathrm{kV}$ XLPE-insulated cable, conducted a series of experiments on cable samples at different aging stages, analyzed the changes in mechanical properties, and examined the physicochemical properties and dielectric strength in relation to aging time.

\section{Experimental Introduction}

2.1. Sample Preparation. Peroxide cross-linked polyethylene is made of low-density polyethylene, and its crystallinity is lower than polyethylene. There are two types of polyethylene cross-linking: radiation cross-linking and peroxide crosslinking. The peroxide cross-linking method is superior to radiation cross-linking in terms of economic performance and processability. The most popular cross-linking agent is dicumyl peroxide. In a high-temperature and high-pressure environment, the hydrogen atoms on the polyethylene chain are "robbed" and the polyethylene molecules that have lost hydrogen atoms are united, which promotes cross-linking.

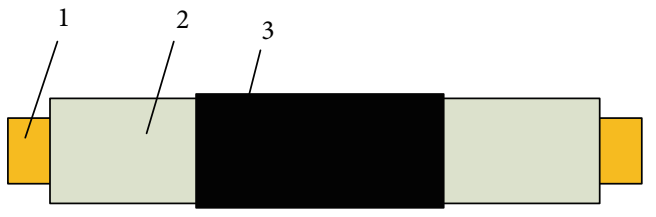

Figure 1: The structure of aging test cables: 1, cable core; 2, XLPEinsulation layer; and 3, outer semiconductive layer.
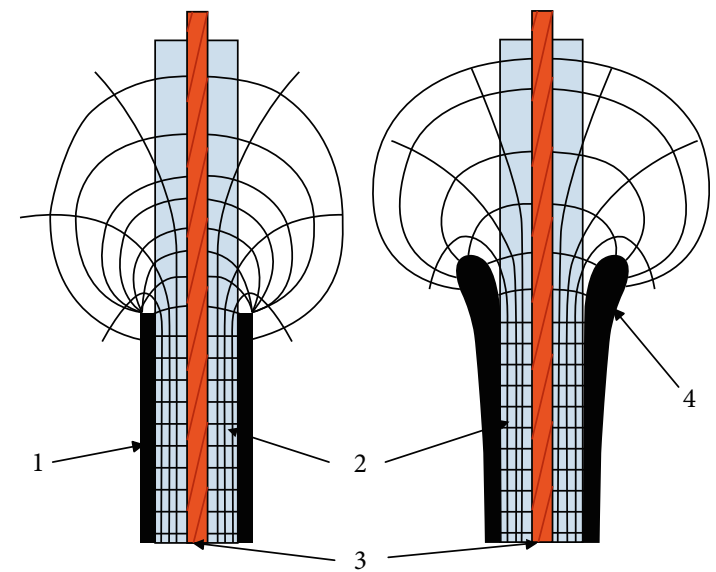

FIgURe 2: The electric field distribution in the outer semiconductive layer incision before and after the installation of the stress cone: 1 , outer semiconducting layer; 2, XLPE insulation; 3, cable core; and 4 , stress cone.

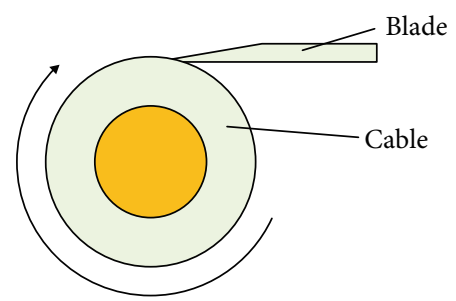

FIgURE 3: Cutting method of cable insulation.

The aging test used a $10 \mathrm{kV}$ XLPE cable produced by Qingdao Cable Limited by Share Ltd., with an XLPE main insulation thickness of $4.5 \mathrm{~mm}$. It is produced by the peroxide cross-linking method. Figure 1 shows how the cable sample was prepared. The total length of the cable is $340 \mathrm{~mm}$. The left and right ends of the outer semiconductive layer were stripped, exposing 90 100 mm length of XLPE insulation. The distortion of the electric field intensity under the effect of AC high voltage easily produced coronas at the edge of the outer semiconductive layer, to the extent that flashovers occurred. In order to create a uniform electric field and prevent flashover, the two sides of the semiconductive layer were designed and installed on the stress cone. The electric field distribution before and after the installation of the stress cone is shown in Figure 2.

After samples of the cable body in each aging stage were taken out, the insulation layer of the cable was cut into thin slices to form a loop, as shown in Figure 3. All samples are taken from the central insulation layer, because of the differences between the inner and outer layers of the cable in the 


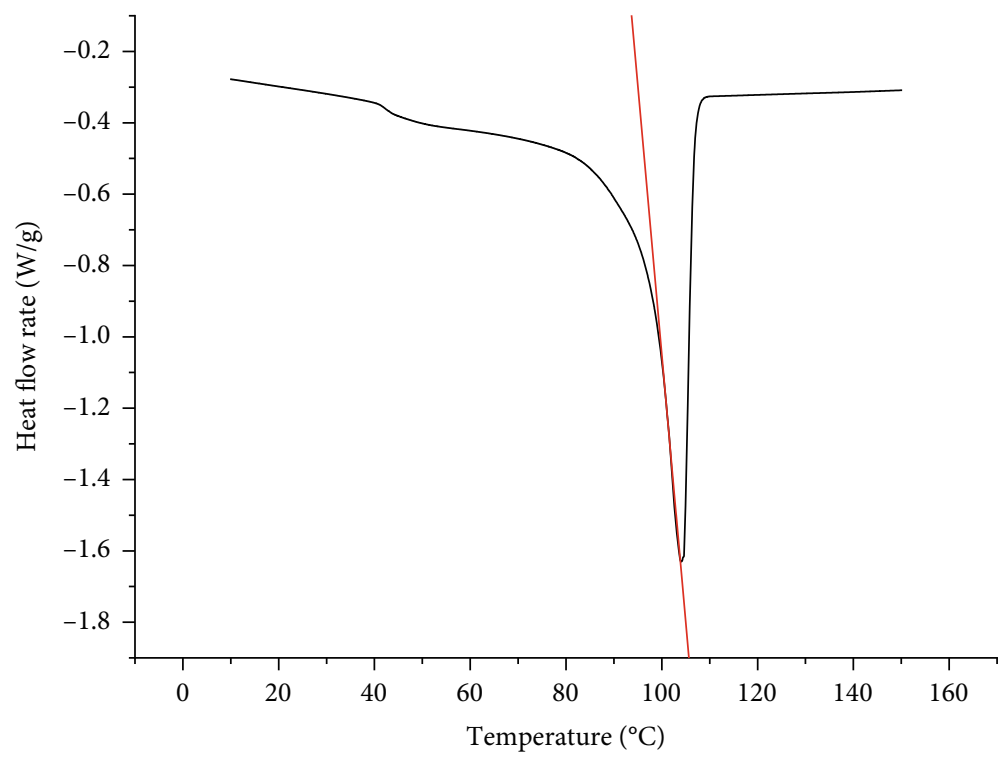

FIGURE 4: Relationship between heat flux and temperature under DSC testing.

production process, as well as differences between the inside and outside layers in terms of electric stress [18] during the aging process.

2.2. Aging Conditions. XLPE material is a type of polymer made up of crystals and an amorphous region. Its crystallization properties are an important factor in dielectric aging and its space charge transport characteristics [19]. The crystallization properties of XLPE can be measured through differential scanning calorimetry (DSC) [20]. Figure 4 shows the relationship between the flow rate and the temperature obtained in the DSC testing of the nonaged XLPE cable. The heat flow rate decreases continuously after $10^{\circ} \mathrm{C}$. The heat flow rate reaches the peak around $103^{\circ} \mathrm{C}$; after $103^{\circ} \mathrm{C}$, the rate gradually increases. When the temperature reaches $114^{\circ} \mathrm{C}$, the heat flow rate stabilizes, which means the crystal region of the sample is completely cracked after $114^{\circ} \mathrm{C}$ [21].

In this study, we select three aging temperatures and carry out a comparative aging test. The first temperature selection is $103^{\circ} \mathrm{C}$ which is the peak temperature of the column crystal region disaggregation. The second temperature selection is $114^{\circ} \mathrm{C}$, which is the temperature of the complete column crystal region disaggregation. The third temperature selection was $135^{\circ} \mathrm{C}$, which is the specified heat aging treatment temperature in IEC 60502-2-2005. In this study, the rated phase voltage of the cable was $\mathrm{U} 0=8.7 \mathrm{kV}$. Considering the aging time, the highest voltage the cable was able to withstand, the high-pressure casing of the stress cone, and the long-term operation of the high-voltage bushing, we set the applied voltage at $26.1 \mathrm{kV}$, which is 3 times the rated voltage.

The electrical-thermal aging time was divided into five stages. The temperature of the sample aging time and the sampling time interval are shown in Table 1 . The electric heating aging platform device diagram is shown in Figure 5.

2.3. Experiment Introduction. Elongation at the break and tensile strength are two indicators commonly used to reflect
TABLE 1: Sample aging time of each temperature and time interval of sampling.

\begin{tabular}{lccc}
\hline Aging temperature & $103^{\circ} \mathrm{C}$ & $114^{\circ} \mathrm{C}$ & $135^{\circ} \mathrm{C}$ \\
Electric stress & & AC voltage $26.1 \mathrm{kV}$ & \\
Total aging time (day) & 375 & 200 & 150 \\
Sampling interval (day) & 75 & 40 & 30 \\
\hline
\end{tabular}

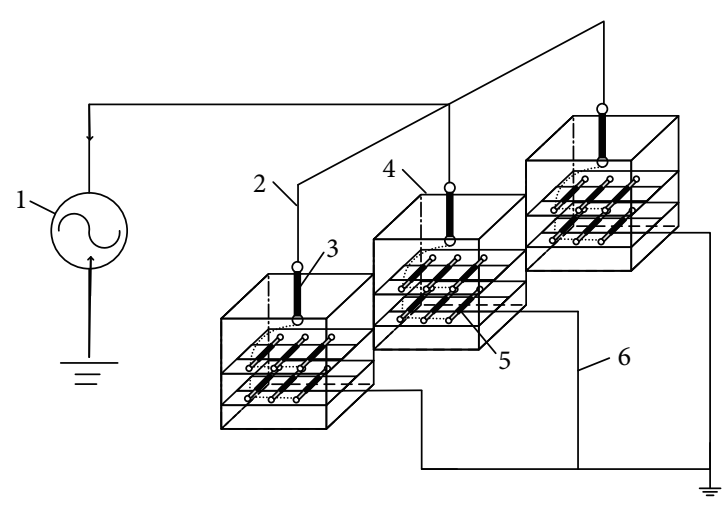

Figure 5: The structure of electric heat aging test platform: 1, AC transformer; 2 , conducting rod; 3 , high-voltage bushing; 4 , aging box; 5 , cable sample for aging; and 6 , ground wire.

the mechanical properties of insulating materials. According to IEC 60811-1-1: 2001 ("General Test Methods for Insulation and Sheathing Materials of Electrical and Optical Cables Part 1-1: General Test Methods-Thickness and Dimension Measurement-Mechanical Performance Test"), elongation at the break and tensile strength can be measured by a CWT6502 microcomputer electronic universal testing machine, and the tensile speed is $250 \pm 50 \mathrm{~mm} / \mathrm{min}$.

A differential scanning calorimeter (DSC) can accurately and conveniently measure the oxidation induction time (OIT) of XLPE cables. At a certain temperature, the oxidation induction time refers to the time when the test sample 


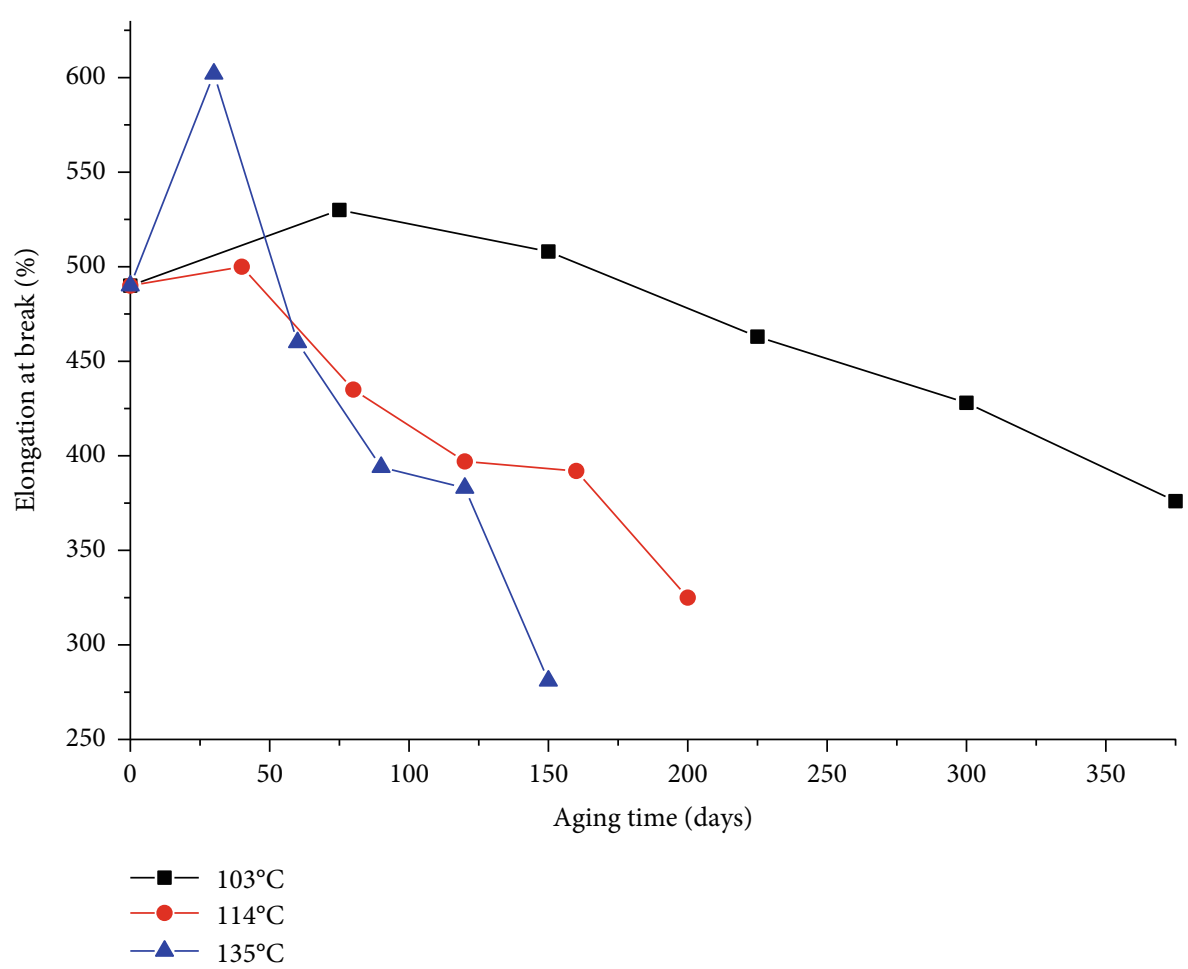

FIGURE 6: Changing curve of elongation at the break with aging time at 3 temperatures.

is switched from the nitrogen environment to the oxygen environment to the time when the oxidation reaction occurs automatically. The start temperature of the experiment is room temperature, and the temperature is increased at a rate of $10^{\circ} \mathrm{C} / \mathrm{min}$ until $200^{\circ} \mathrm{C}$.

We were able to analyze the microstructure and cell information of the crystal using crystal X-ray diffraction (XRD). In semicrystalline polymers like XLPE, the crystallinity can be obtained through X-ray diffraction. The X-ray diffraction test conditions are $\mathrm{CuK} \alpha$ radiation $(\lambda=0.154 \mathrm{~nm})$, tube voltage of $40 \mathrm{kV}$, tube current of $30 \mathrm{~mA}$, scanning range of $10^{\circ} \sim 30^{\circ}$, scanning rate of $4^{\circ} / \mathrm{min}$, and $0.02^{\circ}$ sampling space.

The change of the structure was analyzed by obtaining the characteristics of the infrared spectrum of the absorption peak material containing the functional groups $[20,22]$. Samples from the various aging stages were cleaned with anhydrous alcohol. After drying at room temperature, they were put in the Fourier transform infrared spectrometer for testing. The test conditions were scanning number: 32, resolution: 4, and wave number range: 4000 400.

The sample breakdown voltage reflects the dielectric strength. In this study, two methods were used to test the breakdown voltage of the cable sample. The first method was in accordance with the IEC 60243-1-1998 ("Methods of Test for Electric Strength of Insulating Materials") conventional breakdown field strength test method. In this method, $50 \mathrm{~Hz}$ AC voltage was applied, and the voltage increasing speed was $500 \mathrm{~V} / \mathrm{s}$ [23]. The second method, referred to as the "pre-AC voltage breakdown strength" method, tested the breakdown field strength after application of AC voltage. An electric field of $40 \mathrm{kV} / \mathrm{mm}$ was applied to the sample for 4 hours before the breakdown test. Then, on the basis of
$40 \mathrm{kV} / \mathrm{mm}$, with a $500 \mathrm{~V} / \mathrm{s}$ voltage increasing speed test, a sample was taken of the breakdown field strength. The preAC voltage breakdown strength method was used to study the influence of the AC charge injected into the sample and its effect on the breakdown field strength.

The data used to support the findings of this study are included within the article.

\section{Results and Analysis}

\subsection{Mechanical Properties}

3.1.1. Elongation at the Break and Tensile Strength. Figures 6 and 7 show that elongation at the break and the tensile strength of the aging samples at three temperatures present a similar change rule-in all, there is first an increase and then a decreasing trend as aging time increases. Elongation at the break and the tensile strength both increase in the first stage of sampling, and then they begin to decline in the second stage. Elongation at the break and tensile strength in the late aging stage are lower than those in the nonaged sample. As the aging temperature increases, the decreasing speed of the elongation at the break and tensile strength rapidly decreases. At the fifth aging stage, elongation at the break of the aging samples decreases from $490 \%$ of the nonaged sample to $281 \%, 325 \%$, and $376 \%$ at $103^{\circ} \mathrm{C}, 114^{\circ} \mathrm{C}$, and $135^{\circ} \mathrm{C}$, respectively. The tensile strength decreases from $20.0 \mathrm{~N} / \mathrm{m}^{2}$ of the nonaged sample to $17.7,15.5$, and $14.6 \mathrm{~N} / \mathrm{m}^{2}$, which shows that the mechanical strength decreases significantly.

Figures 6 and 7 show that the changing rule for the elongation at the break and the tensile strength has the changing 


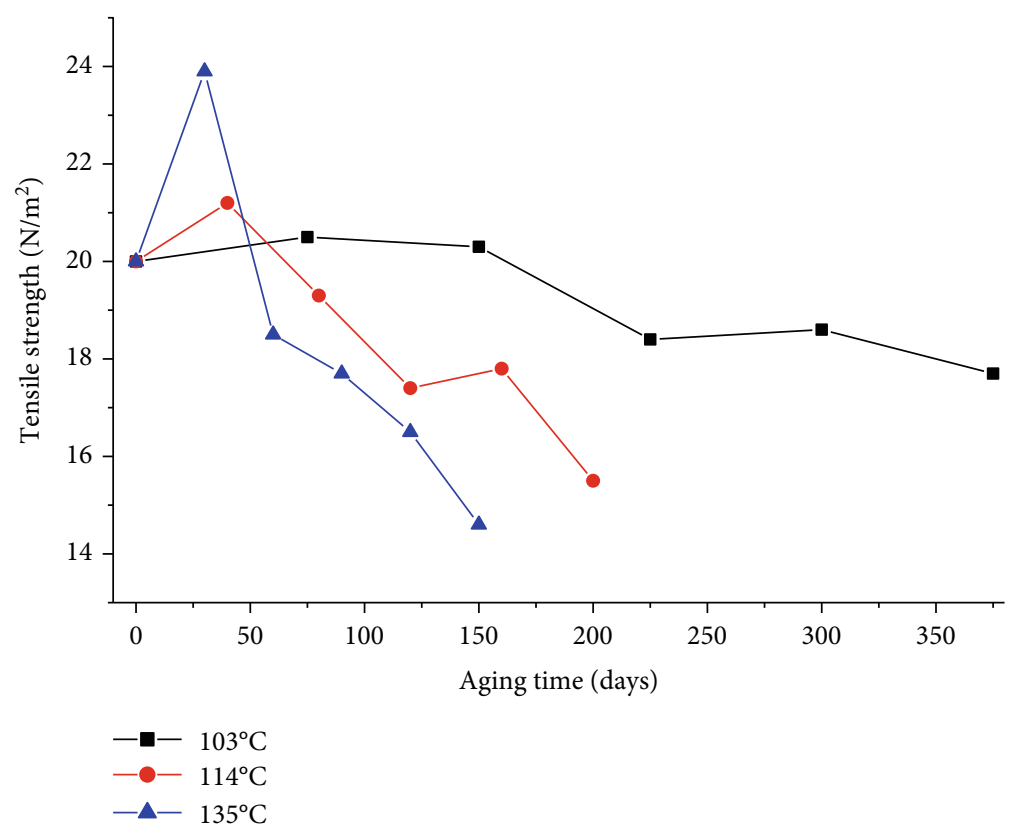

Figure 7: Changing curve of tensile strength with aging time at 3 temperatures.

trend of an initial increase followed by a decrease. In the early stage of aging, the polyethylene molecules recombine, the network structure strengthens, and the mechanical strength of the material is enhanced. In mid- and late aging, the chemical bond of the XLPE cable fracture and the network structure is damaged, which decreases the mechanical strength of the material.

\subsection{Physicochemical Properties}

3.2.1. Oxidation Induction Time. Oxidation induction time of aging cables was tested by the OIT test, which can show the oxidation resistance of the XLPE cable. As shown in Figure 8 , as the aging time increases, the oxidation induction time decreases in general. In the early and middle stages of aging, the decreasing trend is obvious. In late aging, the oxidation induction time rises slightly.

In the early and middle stages of aging, there are two reasons for the decreasing trend. As the aging time increases, the antioxidants added in the manufacturing process gradually decrease, which makes the oxidation resistance of XLPE decrease and the oxidation induction time decrease. When the XLPE cables are aged, the chemical bond of the cable insulation material fractures. Macromolecular chains are broken into small molecular chains, generating mare branched chains and free radicals, which are easily oxidized, so the oxidation induction time decreases. In late aging, the antioxidants are almost completely consumed, and the antioxidants have little effect on the oxidation resistance. There are small molecular chains, which are easily recombined to large molecular chains, and the large molecular chains are not easily oxidized. Therefore, the oxidation resistance of XLPE increases and the oxidation induction time rises slightly. Oxidation induction time and elongation at the break and tensile strength of the aging samples at three tem-

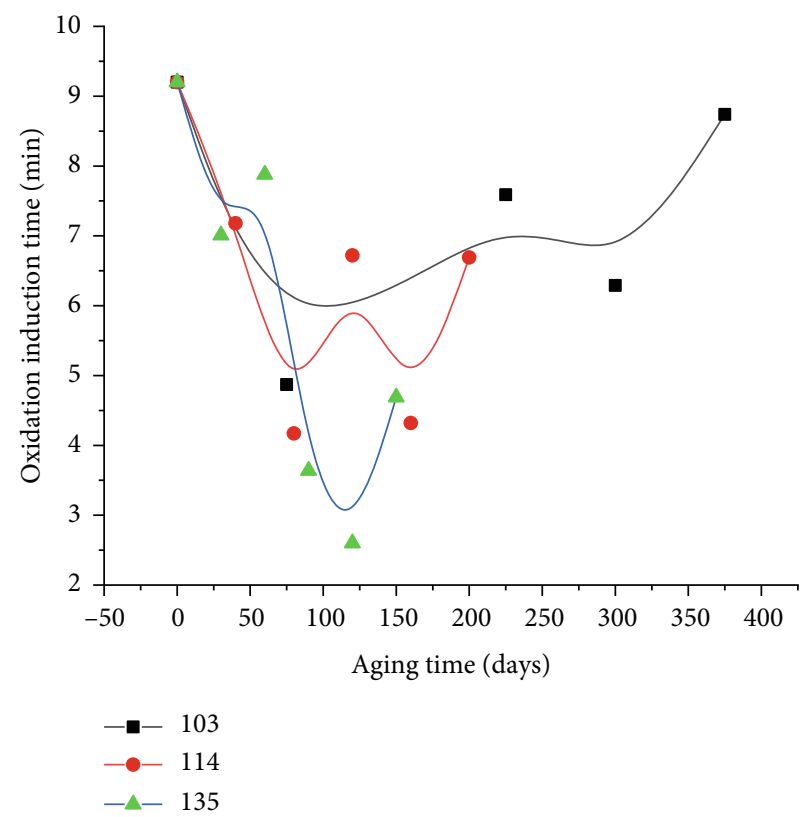

Figure 8: Changing curve of oxidation induction time with aging time at three temperatures.

peratures present a similar change rule-there is a decreasing trend as aging time increases. That shows when the XLPE cables are aged, the chemical bond of the XLPE cable fractures, and the network structure is damaged, which decreases the mechanical strength and the oxidation resistance of the material.

3.2.2. The Degree of Crystallinity. Sliced samples of aging cables were tested by X-ray diffraction. Figures 9(a)-9(c) display the $\mathrm{X}$-ray diffraction patterns at different aging stages of samples at $103^{\circ} \mathrm{C}, 114^{\circ} \mathrm{C}$, and $135^{\circ} \mathrm{C}$. 


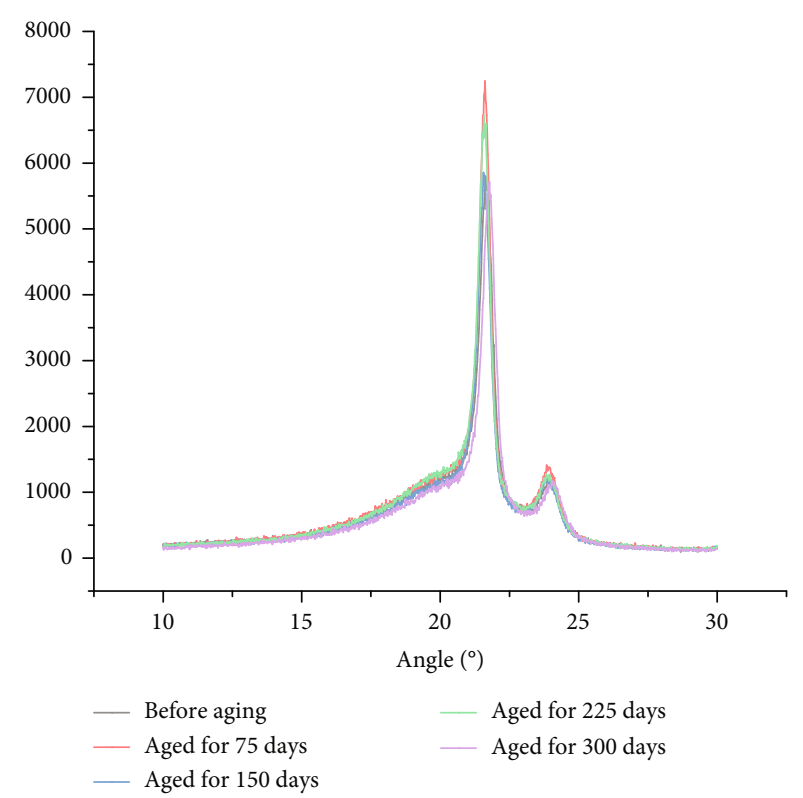

(a) At $103^{\circ} \mathrm{C}$

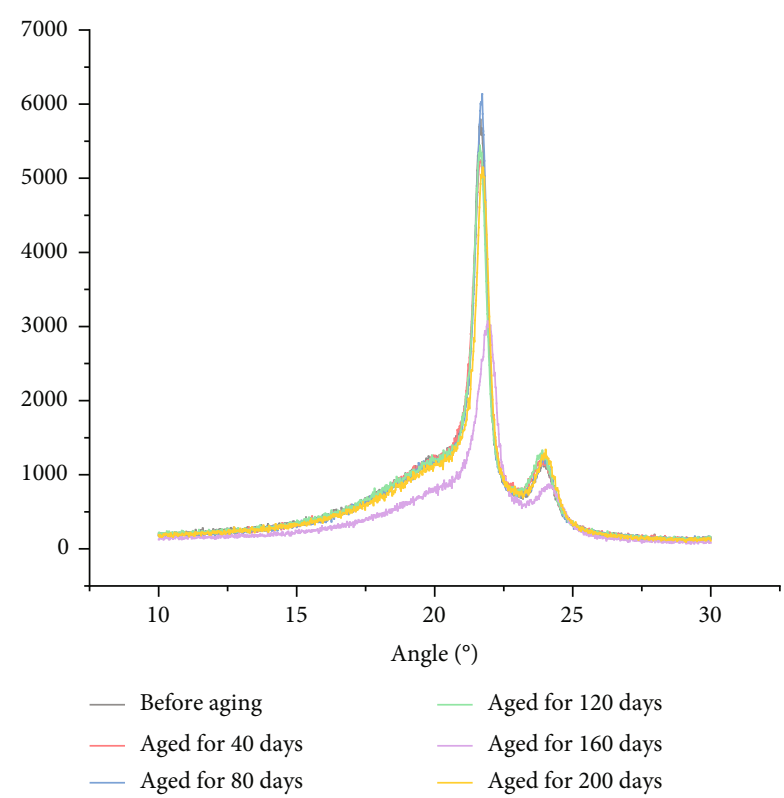

(b) At $114^{\circ} \mathrm{C}$

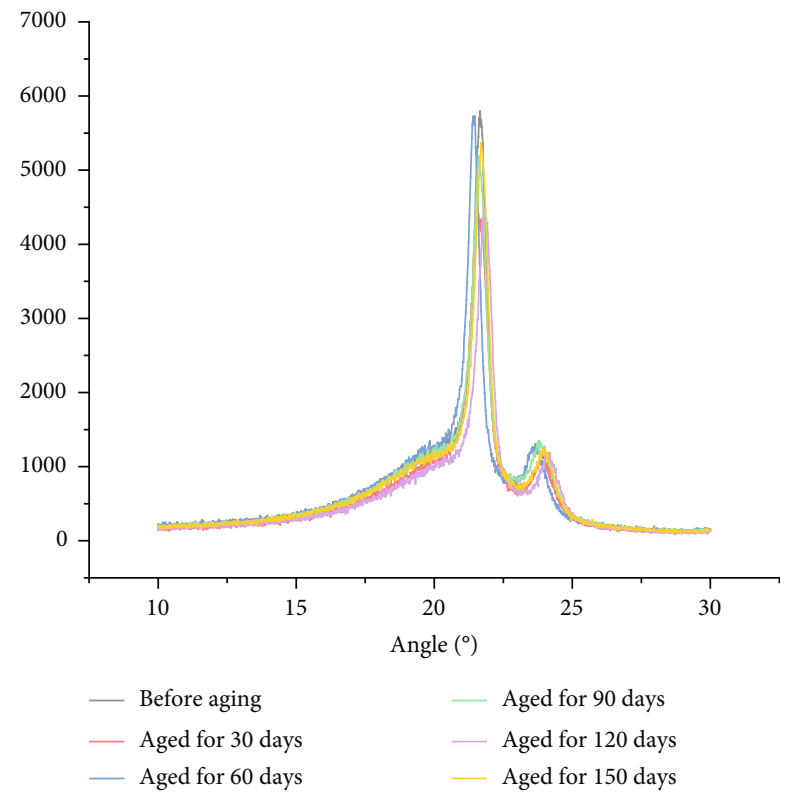

(c) At $135^{\circ} \mathrm{C}$

FIgURE 9: XRD curve at different aging stages.

The XRD curve of the three temperatures at each aging stage has two diffraction peaks: at around $21^{\circ}$, there is a peak that corresponds to the crystal (110) plane; at around $23^{\circ}$, the diffraction peak corresponds to the (200) plane. The diffraction peak position for each aging stage has no obvious changes, which illustrates that the crystal form remains the same. There is some displacement and there were small changes in the interplanar spacing.

The crystallinity can be calculated from the XRD curve by using the peak separation method [24]. We used the XRD pattern processing software Jade5.0 and divided the fitted peaks of the XRD curve, as shown in Figure 9. We used a formula to calculate the degree of crystallinity as it changed with temperature; its curve is shown in Figure 10.
As shown in Figure 11, at each of the three temperatures, the crystallinity trend first decreases, then increases, and then decreases again through the stages of aging, forming an " $\mathrm{N}$ " shape. In the first stage, the crystallization decreases at each of the three temperatures. At the higher temperatures, the degree of crystallinity declines at a faster rate. In the second aging stage, the degree of crystallinity increases. At $103^{\circ} \mathrm{C}$ and $135^{\circ} \mathrm{C}$, the degree of crystallinity decreases at the third aging stage. At $114^{\circ} \mathrm{C}$, the degree of crystallinity decreases in the fourth aging stage. In the nonaged samples, the crystallinity was $50.21 \%$ up until the fifth aging stage. In the aged sample, the crystallinity at $103^{\circ} \mathrm{C}, 114^{\circ} \mathrm{C}$, and $135^{\circ} \mathrm{C}$, respectively, decreases to $50.10 \%, 48.14 \%$, and $45.72 \%$. 


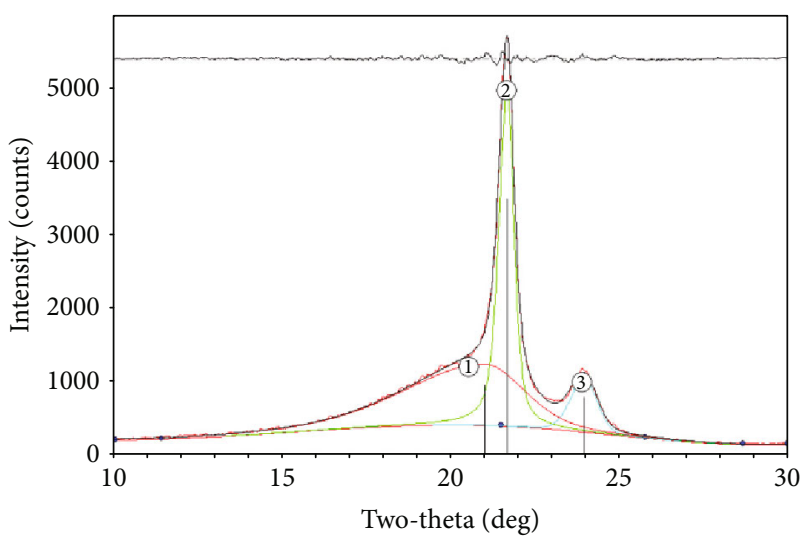

FIGURE 10: XRD curve of the unaged sampleusingJade5.0 to divide the fitted peak. Area 1: amorphous region peak area. Area 2: $2 \theta=21.660^{\circ}$ crystallization peak. Area 3: $2 \theta=21.940^{\circ}$ crystallization peak.

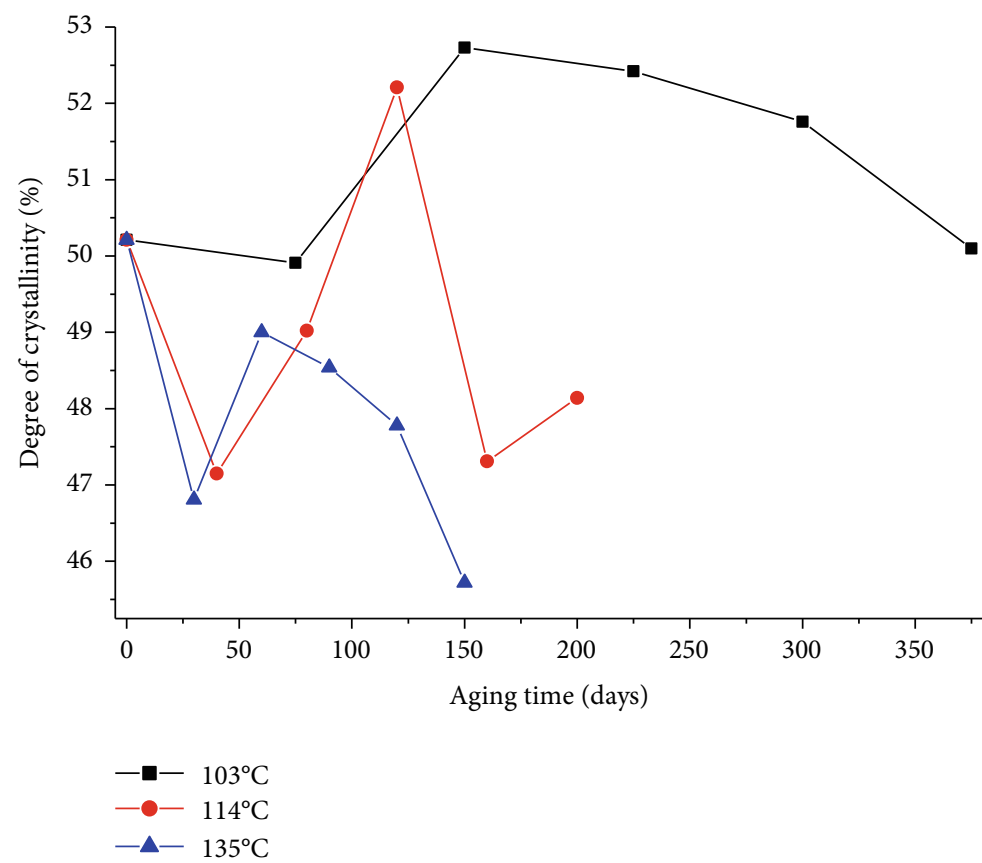

FIgURE 11: Changing curve of the degree of crystallinity with aging time at three temperatures.

In the early aging stage, the degree of crystallinity first decreases and then increases. XLPE is made from lowdensity polyethylene that is cross-linked at a high temperature. Polyethylene molecular chains cannot be completely cross-linked because of constraints in the manufacturing process. Most of the polyethylene molecular chains are cross-linked to form a stable cross-linked network structure, which produces an amorphous region. However, some of the polyethylene molecular chains are not cross-linked-these fill in the network voids among the cross-linked polyethylene. Low-density polyethylene (LDPE) is a semicrystalline polymer. The crystal structure of LDPE is a laminated layer in which a long polymer chain forms through parallel folding, and the crystal regions are surrounded by the amorphous regions. The non-cross-linked polyethylene molecules con- tribute to the degree of crystallinity. The recombination of the polyethylene molecular chains plays a major role in the first aging stage, resulting in an increase in the degree of cross-linking and a corresponding reduction in the proportion of non-cross-linked segments, and the degree of crystallinity decreases. In the second aging stage, the fracture of polyethylene molecular chains plays a major role, resulting in a decrease in the degree of cross-linking and a corresponding increase in the proportion of non-cross-linked segments, causing the degree of crystallinity to increase. In the late aging stage, in the long-term aging effects for the high temperature and high field strength sample, the crystal structure of the crystalline regions is destroyed and integrity of the crystalline regions declines. This leads to a decline in the degree of crystallinity. The experimental results show that 


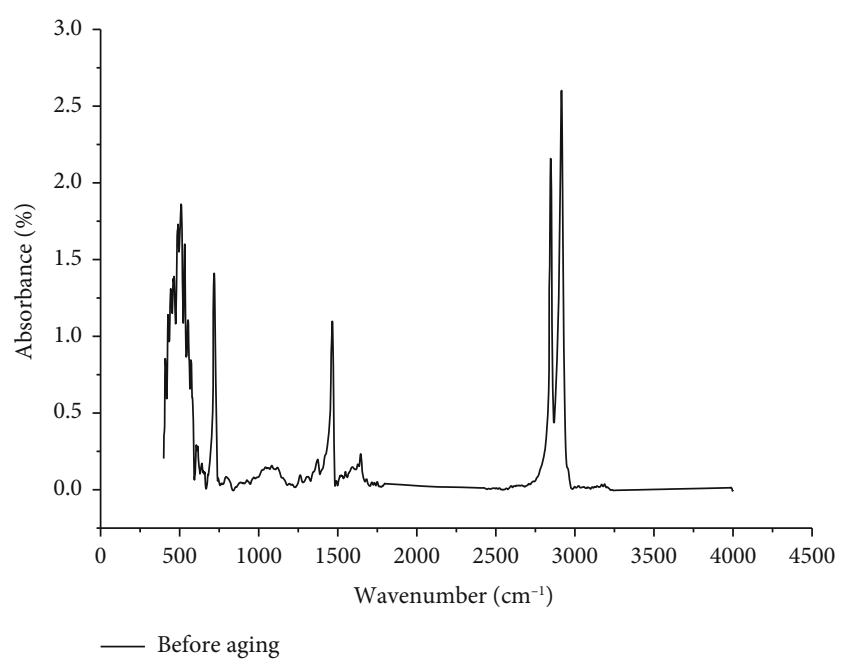

(a) Before aging

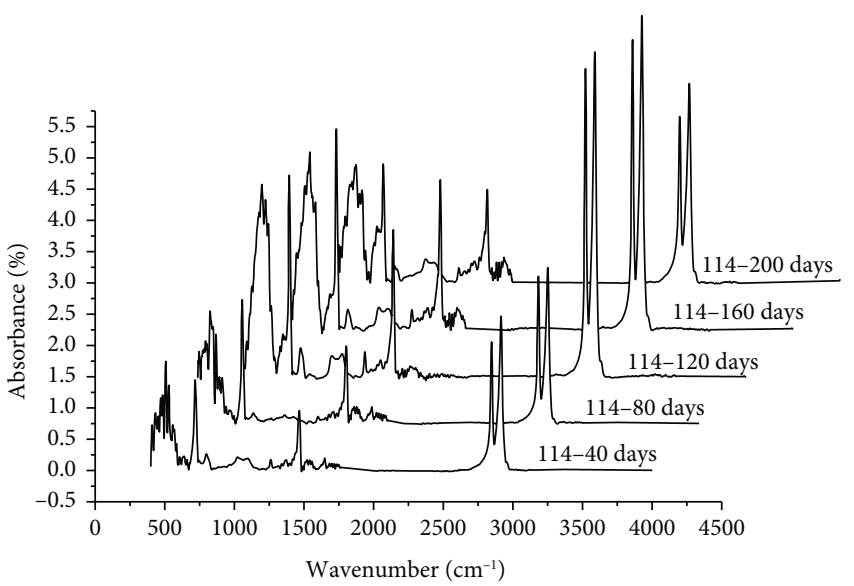

(c) At $114^{\circ} \mathrm{C}$

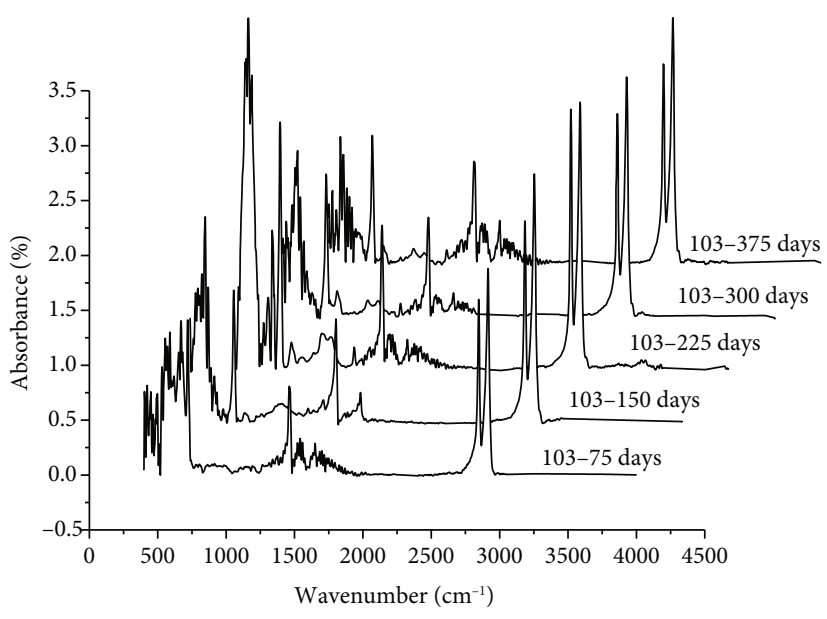

(b) At $103^{\circ} \mathrm{C}$

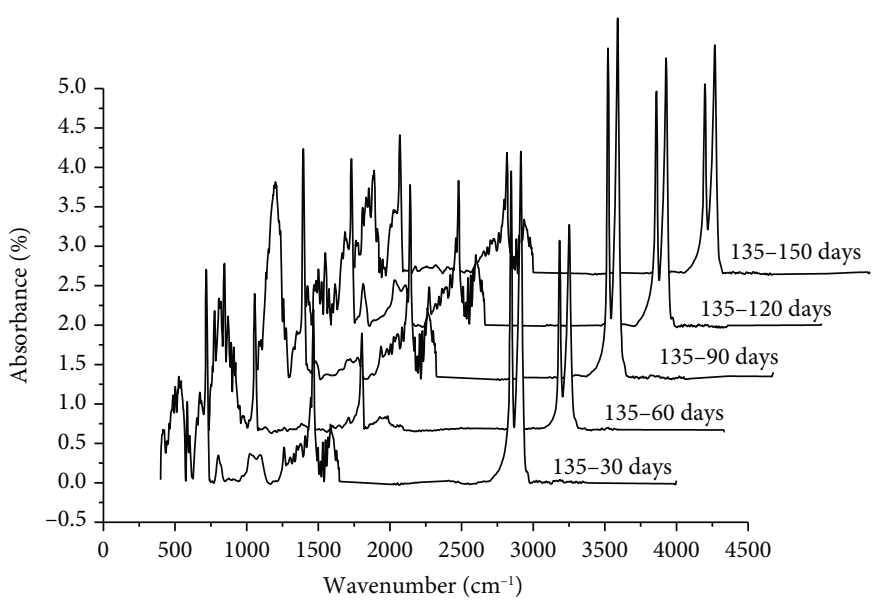

(d) At $135^{\circ} \mathrm{C}$

Figure 12: The infrared spectrogram of aging samples at different stages.

at higher aging temperatures, there is more serious damage to the crystalline region, in the late aging stage.

3.2.3. Infrared Spectrum. If there are a large number of oxygen molecules, such as oxidants, within the XLPE material, the branched alkyl will have oxidation reaction under high temperatures, generating a carbonyl group. Carbonyl derivatives have a characteristic absorption peak at $1720 \mathrm{~cm}^{-1}$. From Figures 12(b)-12(d), we can see that at $1720 \mathrm{~cm}^{-1}$, there were obvious absorption peaks in the aged cable samples. This suggests that a large number of carbonyl groups were not generated at different stages of aging at $103^{\circ} \mathrm{C}, 114^{\circ} \mathrm{C}$, and $135^{\circ} \mathrm{C}$. There are two reasons for this. The $10 \mathrm{kV}$ XLPE cable has joined the antioxidant in the manufacturing process, which inhibits the oxidation of the XLPE chain reaction. Further, the outside layer of the XLPE cable is tightly wrapped with an insulation semiconductive layer, which isolates it from the air. Advanced production technology makes the insulating material microstructure dense, reduces the quantity of microholes, and reduces the amount of oxygen, water, and other impurities. All of these factors minimize the oxidation reaction. The results of this study showed that once the cable sample is electrically-thermally aged, there is minimal carbonyl production and the degree of thermal oxidation is low due to modern manufacturing technology.

\subsection{Electrical Properties}

3.3.1. The Space Charge Quantity of Three Temperatures. Space charge is closely related to aging properties of materials, and the charge quantity reflects the trap density [25]. In this experiment, we adopt a new data processing method, the all-phase average method, which averages the charge waveforms of 32 symmetrical phases, and the space charge waveform obtained by the average phase averaging method has obvious characteristics. This section uses the all-phase average waveforms of total amount of charge under $6 \mathrm{~h} \mathrm{AC}$ pressure to reflect the aging stage of the cable. Figure 13 gives the all-phase average waveforms of the cable at $103^{\circ} \mathrm{C}, 114^{\circ} \mathrm{C}$, and $135^{\circ} \mathrm{C}$ in $6 \mathrm{~h}$. 


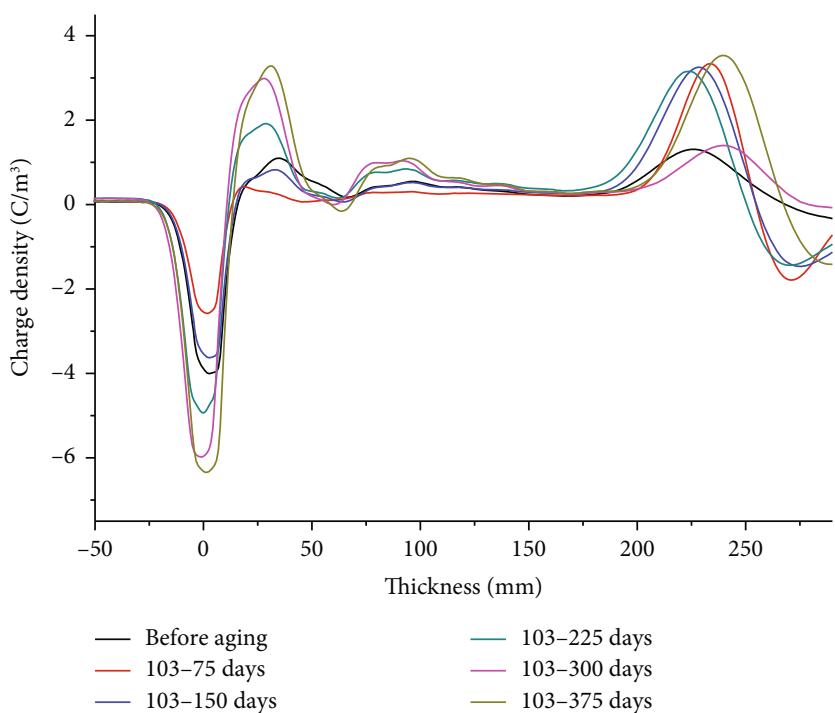

(a) At $103^{\circ} \mathrm{C}$

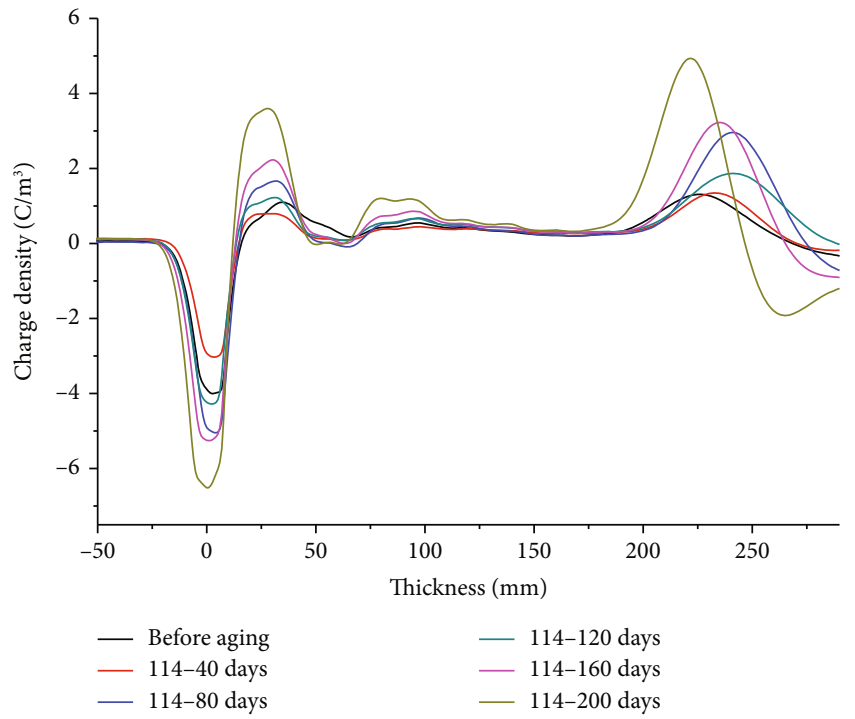

(b) At $114^{\circ} \mathrm{C}$

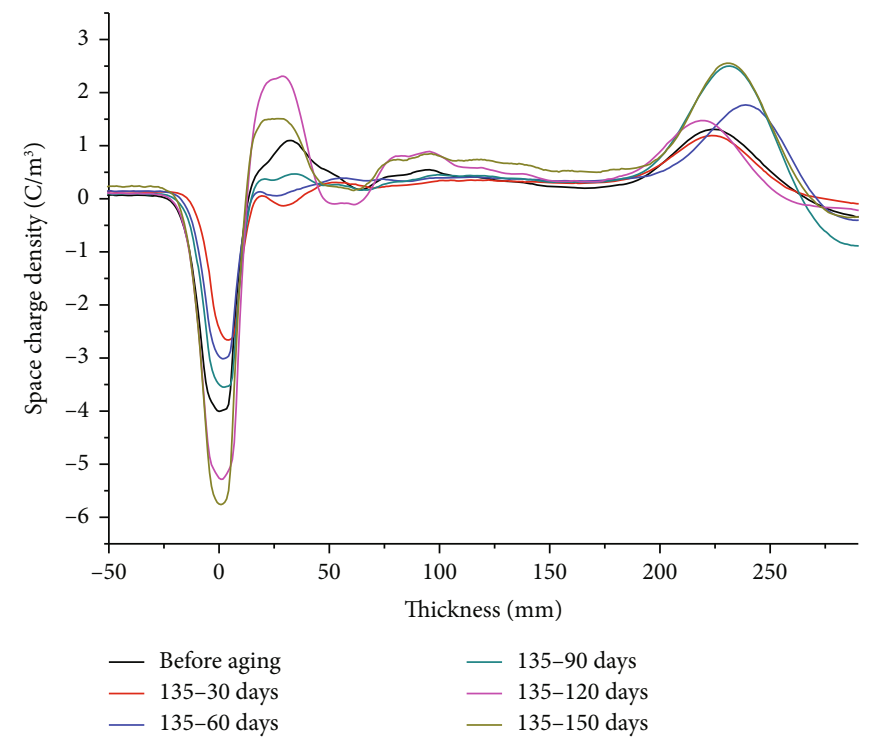

(c) At $135^{\circ} \mathrm{C}$

FIgURE 13: All-phase average charge waveform of cable peelings after $6 \mathrm{~h}$ AC voltage application.

According to the following formula,

$$
Q=\int|\rho(x, t)| d x
$$

the total amount of space charge of each wave in Figure 13 is calculated, and the change characteristics of the total amount of AC space charge with aging time can be obtained. Figure 14 depicts the curve of the all-phase average waveforms of the cable section at $103^{\circ} \mathrm{C}, 114^{\circ} \mathrm{C}$, and $135^{\circ} \mathrm{C}$ under AC pressure in $6 \mathrm{~h}$.

It can be seen that the space charge quantity of three temperatures increases with the aging time. At the beginning, the amount of AC space charge decreased slightly. From the second stage, the charge amount increased gradually, and the space charge quantity at the fifth stage at each temperature was far greater than the amount of the charge before aging. This indicates that the number of defects in XLPE-insulation materials decreases in the early stage of aging and increases greatly in the middle and late stages of aging.

After aging, the trap density of the cable insulation increased, which improves the ability of the cable insulation medium to capture the space charge. The OIT test can also show that the chemical bond of the cable insulation material fractures, so the branched chains and free radicals increase, which increases the trap density of cable insulation. As the aging deepened, the number of traps increased and the number of electrons remaining in the cycle wave and the amount of charge accumulated for a long time which resulted in increase of the ability to accumulate charge in the dielectric strength. The accumulation of space charge caused electric field distortion and energy transfer and release, resulting in more traps. Therefore, the accumulation of charge and the 


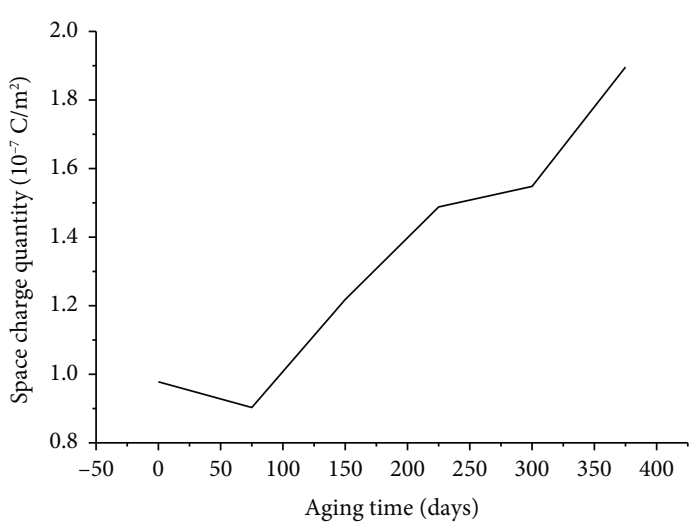

(a) At $103^{\circ} \mathrm{C}$

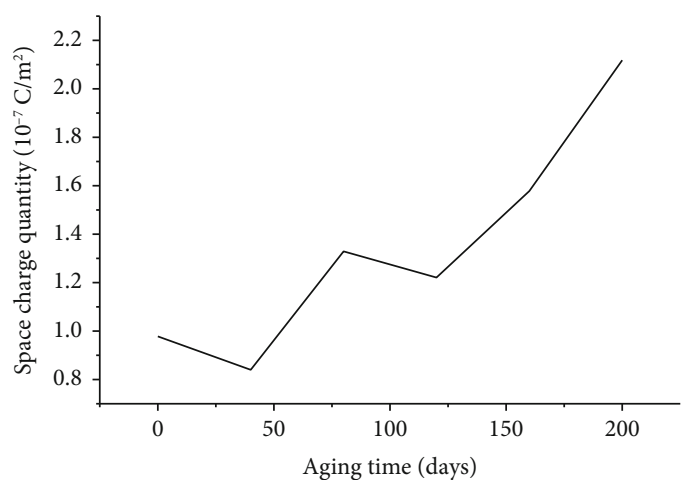

(b) At $114^{\circ} \mathrm{C}$

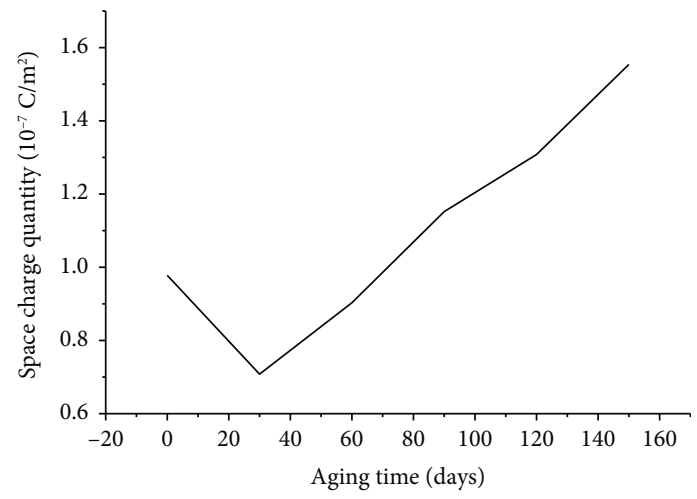

(c) At $135^{\circ} \mathrm{C}$

Figure 14: AC space charge quantity of cable peelings in different aging times.

increase of trap density formed a positive feedback, and AC space charge presented a trend of gradual accumulation with aging time.

3.3.2. Dielectric Strength. Figure 15 shows the samples at $103^{\circ} \mathrm{C}, 114^{\circ} \mathrm{C}$, and $135^{\circ} \mathrm{C}$ using conventional methods of breakdown field strength. The figure shows that overall, the breakdown field strengths of the samples decrease with aging time, with some fluctuation. The first four stages of the breakdown field strength gradually decreased at $103^{\circ} \mathrm{C}$ but increased in the fifth phase. The breakdown field strength alternatively increases and decreases at $135^{\circ} \mathrm{C}$. At $114^{\circ} \mathrm{C}$, the breakdown field strength varies greatly with aging time; in the fifth aging stage, the amplitude of the breakdown field strength decreases slightly compared with the nonaged sample. Therefore, the conventional method of testing breakdown strength with aging time does not produce nonmonotonic decline, and it cannot characterize the degree of aging very well.

In addition to the conventional method to test the breakdown field strength, we also tested the breakdown field strength after application of the AC voltage (pre-AC voltage breakdown strength). Figure 16 shows the change curve of the breakdown field strength change with aging time. In this figure, it can be seen that the pre-AC voltage breakdown strength of the sample under the three temperatures decreases monotonically with the aging time, and the rate of decrease is proportional to the aging temperature. This is because the AC space charge is injected into the interior of the material and is trapped by the defects that are generated under electrical-thermal aging. As the aging degree deepens, there are more trapped charges in the cable insulation. This distorts the electric field, which leads to a decrease of the breakdown field strength. Our study shows that the correlation between the pre-AC voltage breakdown strength and the aging time is much larger than the conventional breakdown field strength. The pre-AC voltage breakdown strength is more suitable for use as the characteristic index for the aging degree of cable insulation.

\section{Conclusion}

In this paper, $10 \mathrm{kV}$ XLPE-insulated cables were aged at $26.1 \mathrm{kV} \mathrm{AC}$ voltage and at three temperatures of $103^{\circ} \mathrm{C}$, $114^{\circ} \mathrm{C}$, and $135^{\circ} \mathrm{C}$ and were tested in five aging stages for degree of mechanical strength, $\mathrm{X}$ - ray diffraction, oxidation induction time, infrared spectroscopy, space charge, and dielectric strength. Through analysis of the results of these experiments, the aging characteristics of XLPE cable were obtained, which are as follows:

(1) The oxidation induction time and the mechanical properties have the same changing trend with aging time, which is decreasing in general. This phenomenon can be related to the fracture of the chemical bond of the XLPE cable and the damage of the 


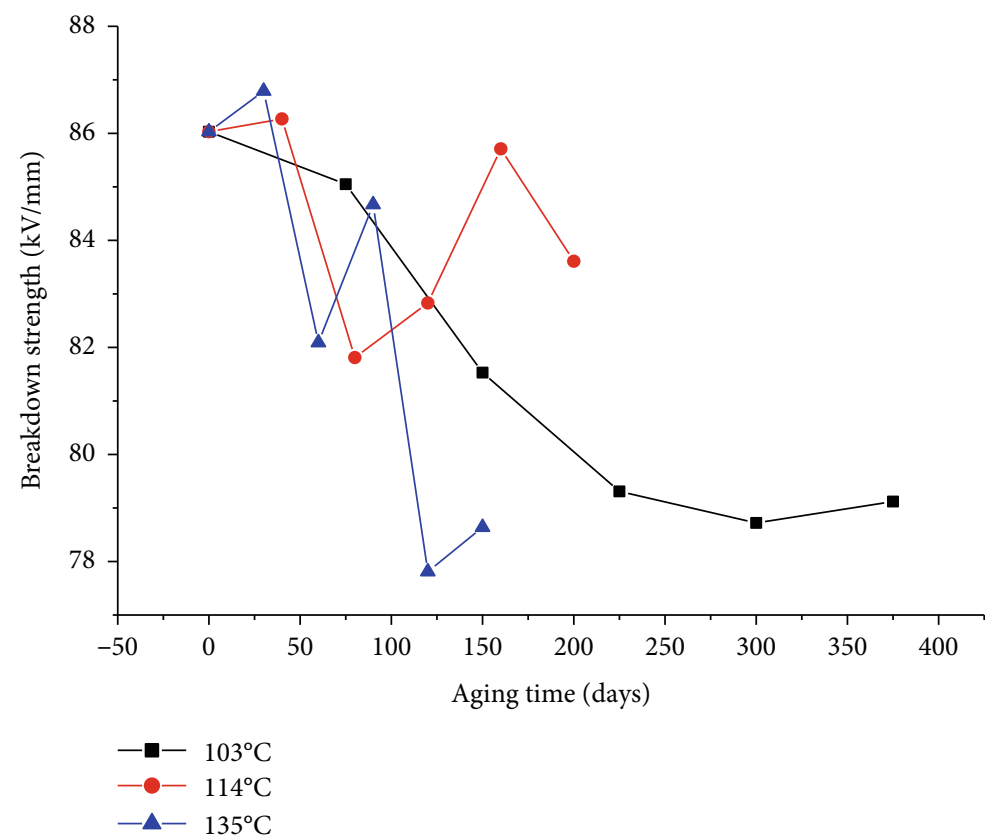

FIgURE 15: Changing curve of conventional breakdown field strength with aging time under three temperatures.

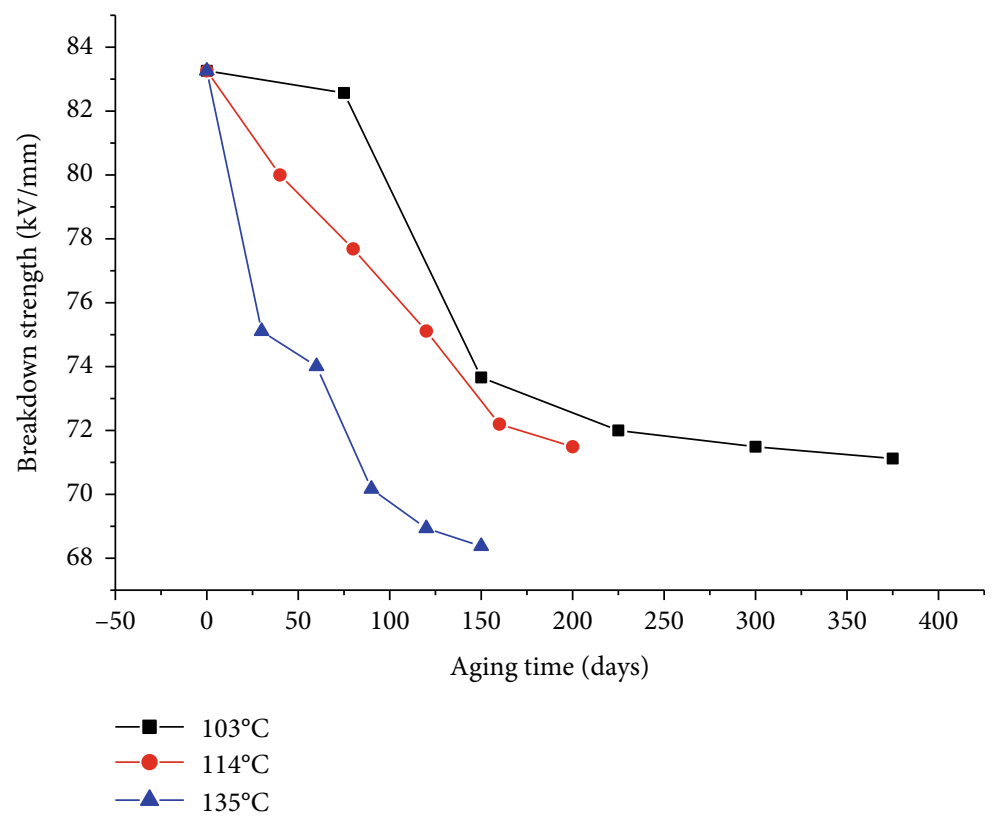

FIGURE 16: Changing curve of pre-AC voltage breakdown strength with aging time at three temperatures.

network structure. When the cable is aged, the chemical bond of the cable insulation material fractures. Macromolecular chains are broken into small molecular chains, generating more branched chains and free radical increase. Therefore, mechanical strength weakens and the oxidation time decreases

(2) The accumulation of charge and the increase of trap density have a positive feedback, and the AC space charge presented a trend of gradual accumulation with aging time. After aging, the chemical bond of the cable insulation material fractures, so the branched chains and free radicals generate, which increases the trap density of cable insulation

(3) The results of the infrared spectrum showed that the aged cable sample did not contain a large amount of carbonyl groups. This may be caused by two reasons: firstly, antioxidants were added in cable insulation materials during the manufacturing process, which played a role in inhibiting the oxidation reaction; secondly, the XLPE cable insulation layer is tightly 
wrapped by a semiconductive layer; thus, it is isolated from the oxygen in the air. The advanced production technology makes the microstructure of the insulating material pure and reduces the number of micropores which may provide the residence space of impurities such as oxygen and water

(4) The breakdown field strength of the cable sample showed a decreasing trend with aging time. In particular, the pre-AC voltage breakdown strength was found to decrease monotonically, and the rate of decrease was proportional to the aging temperature. The reason is that defects generate in the cable samples under aging and capture the space charge in the AC voltage application process which distorts the electric field, so the breakdown strength obviously decreased. Therefore, the pre-AC voltage breakdown strength can be a characteristic index to reflect the degradation degree of cable insulation

\section{Data Availability}

The data used to support the findings of this study are included within the article.

\section{Conflicts of Interest}

The authors declare that they have no conflicts of interest.

\section{Acknowledgments}

This study was funded by the National Natural Science Foundation of China (Grant No. 51907105) and the Shandong Provincial Natural Science Foundation (Grant No. ZR2019QEE013).

\section{References}

[1] T. Kumazawa, "Application of the AC superposition method to degradation diagnosis of $22 / 33-\mathrm{kV}$ class XLPE cables," Electrical Engineering in Japan, vol. 195, no. 1, pp. 32-39, 2016.

[2] J. Granado, C. Álvarez-Arroyo, A. Torralba, J. A. RosendoMacías, J. Chávez, and M. Burgos-Payán, "Time domain analysis of partial discharges envelope in medium voltage XLPE cables," Electric Power Systems Research, vol. 125, pp. 220-227, 2015.

[3] H. Li, J. Li, W. Li, X. Zhao, G. Wang, and M. A. Alim, "Fractal analysis of side channels for breakdown structures in XLPE cable insulation," Journal of Materials Science: Materials in Electronics, vol. 24, pp. 1640-1643, 2013.

[4] W. Cao, B. He, W. Shen et al., "An approach for economic assessment on oil-paper insulation diagnosis through accelerated aging experiments," EEE Transactions on Dielectrics and Electrical Insulation, vol. 21, no. 4, pp. 1842-1850, 2014.

[5] J. P. Jones, J. P. Llewellyn, and T. J. Lewis, "The contribution of field-induced morphological change to the electrical aging and breakdown of polyethylene," IEEE Transactions on Dielectrics and Electrical Insulation, vol. 12, no. 5, pp. 951-966, 2005.
[6] F. Aras, V. Alekperov, N. Can, and H. Kirkici, "Aging of 154 $\mathrm{kV}$ underground power cable insulation under combined thermal and electrical stresses," IEEE Electrical Insulation Magazine, vol. 23, no. 5, pp. 25-33, 2007.

[7] M. H. Shwehdi, M. A. Morsy, and A. Abugurain, "Thermal aging tests on XLPE and PVC cable insulation materials of Saudi Arabia," in 2003 Annual Report Conference on Electrical Insulation and Dielectric Phenomena, pp. 176-180, Albuquerque, NM, USA, 2003.

[8] L. Bessissa, L. Boukezzi, and D. Mahi, “A fuzzy logic approach to model and predict $\mathrm{HV}$ cable insulation behaviour under thermal aging," Acta Polytechnica Hungarica, vol. 11, pp. 107-123, 2014.

[9] W. Zhan, X. Chu, Z. Shen et al., "Study on aggregation structure and dielectric strength of XLPE cable insulation in accelerated thermal-oxidative aging," Proceedings of the CSEE, vol. 36, pp. 102-110, 2016.

[10] X. Wang, Q. Liu, X. Zhang, K. Wu, C. Zhang, and W. Li, "Study on space charge behavior of XLPE after long-term aging under temperature gradient and DC stress," in 2016 International Conference on Condition Monitoring and Diagnosis (CMD), pp. 741-744, Xi'an, China, 2016.

[11] X. Wang, D. Tu, Y. Tanaka et al., "Space charge in XLPE power cable under dc electrical stress and heat treatment," IEEE Transactions on Dielectrics and Electrical Insulation, vol. 2, no. 3, pp. 467-474, 1995.

[12] G. C. Montanari, G. Pattini, and L. Simoni, "Long - Term behavior of XLPE insulated cable models," IEEE Transactions on Power Delivery, vol. 2, no. 3, pp. 596-602, 1987.

[13] A. Motori, F. Sandrolini, and G. C. Montanari, "A contribution to the study of aging of XLPE insulated cables," IEEE Transactions on Power Delivery, vol. 6, no. 1, pp. 34-42, 1991.

[14] W. Wang, S. Chen, K. Yang, D. He, and Y. L. Yu, "The relationship between electric tree aging degree and the equivalent time-frequency characteristic of PD pulses in high voltage cable," in 2012 IEEE International Symposium on Electrical Insulation, pp. 18-21, San Juan, PR, USA, 2012.

[15] J. C. Fothergill, S. J. Dodd, L. A. Dissado, T. Liu, and U. Nilsson, "The measurement of very low conductivity and dielectric loss in XLPE cables: a possible method to detect degradation due to thermal aging," IEEE Transactions on Dielectrics and Electrical Insulation, vol. 18, no. 5, pp. 1544-1553, 2011.

[16] Y. Liu, H. Liu, L. Yu, Y. Li, and L. Gao, "Effect of thermal stress on the space charge distribution of $160 \mathrm{kV}$ HVDC cable insulation material," IEEE Transactions on Dielectrics and Electrical Insulation, vol. 24, no. 3, pp. 1355-1364, 2017.

[17] X. Chen, A. R. Mantsch, L. Hu, S. M. Gubanski, J. Blennow, and C.-O. Olsson, "Electrical treeing behavior of DC and thermally aged polyethylenes utilizing wire-plane electrode geometries," IEEE Transactions on Dielectrics and Electrical Insulation, vol. 21, no. 1, pp. 45-52, 2014.

[18] E. Enqvist, D. Ramanenka, P. A. A. P. Marques, J. Gracio, and N. Emami, "The effect of ball milling time and rotational speed on ultra high molecular weight polyethylene reinforced with multiwalled carbon nanotubes," Polymer Composites, vol. 37, pp. 1128-1136, 2014.

[19] Z. L. Li, B. X. Du, Z. R. Yang, and J. Li, "Effects of crystal morphology on space charge transportation and dissipation of $\mathrm{SiC} /$ silicone rubber composites," IEEE Transactions on Dielectrics and Electrical Insulation, vol. 24, no. 4, pp. 2616-2625, 2017. 
[20] M.-Z. Li, "Comparison between the test methods for the measurement of the gel content in XLPE insulation compounds," Electric Wire \& Cable, vol. 4, pp. 36-38, 2006.

[21] W. Wang, C. Yue, J. Gu, J. Du, F. Li, and K. Yang, "Status assessment of polymeric materials in mineral oil under electro-thermal aging by frequency-domain dielectric spectroscopy," IEEE Transactions on Dielectrics and Electrical Insulation, vol. 22, no. 2, pp. 831-841, 2015.

[22] W. Wang, D. He, J. Gu, J. Lu, and J. Du, "Electrical-thermal aging characteristic research of polymer materials by infrared spectroscopy," Polymers for Advanced Technologies, vol. 25, no. 12, pp. 1396-1405, 2014.

[23] M. F. Galikhanov, A. A. Guzhova, A. A. Efremova, and A. I. Nazmieva, "Effect of aluminum oxide coating on structural, barrier and electret properties of polyethylene terephthalate films," IEEE Transactions on Dielectrics and Electrical Insulation, vol. 22, no. 3, pp. 1492-1496, 2015.

[24] F. J. Valle-Fuentes, J. Garcia-Guinea, A. Cremades et al., "Lowmagnesium uranium-calcite with high degree of crystallinity and gigantic luminescence emission," Applied Radiation and Isotopes, vol. 65, pp. 147-154, 2007.

[25] J. Li, B. X. Du, X. X. Kong, and Z. L. Li, "Nonlinear conductivity and interface charge behaviors between LDPE and EPDM/SiC composite for HVDC cable accessory," IEEE Transactions on Dielectrics and Electrical Insulation, vol. 24, no. 3, pp. 15661573, 2017. 